\title{
Soybean Varietal Response and Yield Loss Caused by Sclerotinia sclerotiorum
}

\author{
X. B. Yang, P. Lundeen, and M. D. Uphoff, Department of Plant Pathology, Iowa State University, Ames 50011
}

\begin{abstract}
Yang, X. B., Lundeen, P., and Uphoff, M. D. 1999. Soybean varietal response and yield loss caused by Sclerotinia sclerotiorum. Plant Dis. 83:456-461.

Soybean Sclerotinia stem rot, caused by Sclerotinia sclerotiorum, has recently emerged from being a minor problem in areas where soybeans of maturity groups 0 to I are grown to a significant cause of soybean yield losses in the north-central region, which produces $80 \%$ of soybean in the United States. Studies were conducted in Iowa to quantify varietal response to S. sclerotiorum for cultivars of maturity groups I to III in fields that had uniform infestation histories. Over the course of the study, disease incidence was generally high at the northern Iowa sites but low in central Iowa, with disease incidence of susceptible standards $>60 \%$ and $<30 \%$, respectively. Regression analysis showed that maturity class significantly affected disease incidence, with greater effects in environments where susceptible standard cultivars had high disease incidences. Consistency of varietal response among the environments was quantified using Pearson correlation analysis. When disease incidence was high, varietal responses measured by disease ratings and yield were consistent among locations, but the responses were inconsistent when disease incidence was low. Pearson correlation coefficients ranged from 0.80 to 0.94 for disease incidence and 0.58 to 0.81 for yield among the experiments having high disease incidence in susceptible standards. The relationship between disease incidence and yield was well described by linear regression models with coefficients of determination $\left(r^{2}\right)$ ranging from 0.59 to 0.83 . Based on regression slopes (significant at $P<0.0001$ ), yield losses are estimated to range from 170 to $335 \mathrm{~kg} / \mathrm{ha}$ for each 10 percentage points of disease incidence. Regression analysis also showed that maturity groups had a linear relationship with disease incidence $\left(r^{2}=0.18\right.$ to 0.39 , $P<0.01)$.
\end{abstract}

Soybean Sclerotinia stem rot caused by Sclerotinia sclerotiorum (Lib.) de Bary was first found in the United States in 1946 and reported in 1951 (6). The pathogen spreads from field to field by airborne spores $(1,23)$, sclerotia mixed with seed (11), and possibly within internally infested seed (28). Overwintered sclerotia produce apothecia which release ascospores to infect soybean stems through flowers, which have a narrow infection window for soybeans of determinate growth. The fungal mycelium grows in and outside stems and the infected plants die in late growth stages. Severe disease can occur during an extended period of cool and moist weather (12). The disease was initially a minor production problem, with localized epidemics occurring in some areas of Michigan, Minnesota, and Wisconsin (11) where soybeans of maturity groups 0 to I are grown. It was ranked twelfth before 1991 in disease losses in the U.S. north-central soybean production

Corresponding author: X. B. Yang

E-mail: xbyang@iastate.edu

This project was supported in part by Hatch Act and State of Iowa funds and by the Iowa Soybean Promotion Board.

Accepted for publication 9 February 1999.

Publication no. D-1999-0308-04R

(C) 1999 The American Phytopathological Society region (9). The disease recently has emerged as a major production problem in the north-central region, with outbreaks occurring in areas where maturity groups I to III are grown. In a survey conducted in 1994 (27), the disease ranked second after soybean cyst nematode as a leading cause of soybean yield loss in the north-central soybean production region. In Iowa, the disease was not recognized as a significant problem until 1992, when severe outbreaks occurred in major soybean production areas of northern and central Iowa. In the 1996 growing season, the disease was at epidemic proportions in many Iowa soybean fields, much more severe than in 1992 and 1994. In 1997, epidemics occurred in northeastern Iowa.

The use of cultivars with field resistance is an important approach in the management of this disease, and the recent epidemics of this disease in the north-central region emphasize the need for field resistance in management of this disease. Early studies in other states in the north-central region and in Canada $(3,5,7,8,13,15-17)$ found differences in varietal response to this disease. Differences in varietal response were also found in dry bean (Phaseolus vulgaris L.) $(2,18)$ and in white bean (22). Grau et al. (13) concluded that field resistance to soybean Sclerotinia stem rot is a heritable trait. Identification of cultivars with field resistance from commercial lines will provide useful information for breeding new lines or germplasm resistance to the disease. Because this disease caused damage in northern parts of the north-central soybean production region, available varietal information on field resistance, which was published a decade ago, is mainly for maturity groups 0 to I. Little information is available on resistance of newer soybean germplasm to Sclerotinia stem rot for regions where soybeans of maturity groups I to III are grown. Significant changes to soybean germplasm occurred before the resurgence of this disease in the north-central region. Information on the response of new germplasm to Sclerotinia stem rot would shed light on breeding resistant cultivars with contemporary materials. Furthermore, differences in varietal response to Sclerotinia stem rot have been observed among soybeans of different maturity but the maturity effect has not been examined. No quantitative analysis has been done for the relationship between maturity and disease incidence. Information of such a relationship will be useful for successful development of resistant cultivars of later maturity groups.

Varietal response to Sclerotinia stem rot can be described by the incidence of disease symptoms or the yield loss corresponding to incidence. The quantitative relationship between disease incidence and yield loss is important to characterize a varietal response and to help growers make economically sound farming decisions. However, information is not available from systematic studies of the relationships between yield losses and disease incidence. Previously reported data $(7,12,14)$ on disease losses were from a limited number of cultivars in a single environment. A quantitative relationship between disease incidence in various environments is needed and is fundamental in improving assessment of the impact of this disease on a regional scale. The objectives of this study were (i) to identify soybean cultivars with field resistance from current commercial germplasm of maturity groups I to III; (ii) to examine the maturity effects on varietal response; and (iii) to develop a quantitative relationship between disease incidence and seed yield.

\section{MATERIALS AND METHODS}

Experimental locations. We conducted studies in multiple locations in central and northern Iowa in 1996 and 1997 by selecting corn-soybean rotation fields which were previously infested with $S$. sclerotiorum. In 1996, experiments were conducted at three locations: Ames in central Iowa, Humboldt in north-central Iowa, and 
Kanawha in north-central Iowa, about 50 $\mathrm{km}$ east of Humboldt. The field at the Humboldt site was a commercial cornsoybean production field which was known to be naturally infested with Sclerotinia stem rot since 1992, and a survey in 1994 showed a disease incidence of about $70 \%$. The Kanawha field, located at the Iowa State University (ISU) Northern Research Farm, was artificially infested with sclerotia of S. sclerotiorum in the fall of 1994 at an approximate density of 80 sclero$\mathrm{tia} / \mathrm{m}^{2}$, and again in the fall of 1995 using infested soybean debris at a rate of approximately $1,200 \mathrm{~kg} / \mathrm{ha}$ of debris collected after harvest from a field with greater than $50 \%$ disease incidence. The experiment at Ames was conducted at the ISU Hinds Research Farm in a field that was uniformly infested with sclerotia at a density of $80 \mathrm{sclerotia} / \mathrm{m}^{2}$ in spring 1995 and then planted to soybean.

The experiments in 1997 were conducted at Ames in central Iowa and Mason City in north-central Iowa. The field at Ames was also at the ISU Hinds Research Farm but was different from the field used in 1996. The Hinds Farm field was planted to cv. Williams 82 in 1996 and had a mean disease incidence greater than $60 \%$. The field at Mason City was located at the Northern Iowa Area Community College Research Farm and had severe Sclerotinia stem rot in 1996.

Cultivars. A total of 63 cultivars from 25 sources in 1996 and 64 cultivars from 29 sources in 1997 were studied. The cultivars which represented current germplasm from public and private sources ranged from groups I to III in maturity, based on information provided by seed companies or universities. Of the 63 to 64 cultivars, 19 were entered in both years. Based on our field observations and previously reported studies $(3,7,8,13)$, Novartis S19-90 and Corsoy 79 were selected as resistant standard cultivars and Asgrow A2242 and Williams 82 as susceptible standard cultivars. There were highly significant differences $(P<0.0001)$ in disease incidence among these four cultivars, with consistency across replicates in these preliminary tests (24). These four cultivars, used as resistant and susceptible checks in our preliminary test, were included in the 2-year study.

Planting. A randomized complete block design with four replications was used at each location. Soybeans at each location were planted in May to ensure a robust growth of soybean for maximum yields in Iowa (25). Because previous studies (12) indicated that a dense soybean canopy favors the development of Sclerotinia stem rot, a row spacing of approximating $38 \mathrm{~cm}$ was used, with a planting density of 20 to $26 \mathrm{seed} / \mathrm{m}$ of row. Plots were maintained according to the level of soil fertility and previous planting history at individual locations. Plots ranged from 3.5 to $5.5 \mathrm{~m}$ in length and plot width varied from 6 to 8 rows based on the planter used. Each plot at the Mason City location consisted of four rows of a test cultivar bordered with one row of Kenwood, a moderate susceptible cultivar, on each side. Plots were planted close together to duplicate field production conditions. Fields were managed with normal weed control operations using herbicides excluding lactofen and sodium salts of acifluorfen, which have been observed to cause foliar injury to soybean. Weeds that emerged after application of herbicides were removed by hand. No cultivation was made after midJune to preserve soil moisture, because reduction in soil moisture by mid-season cultivation may affect sclerotia germination. At maturity, the center rows of the plots were harvested with an Almaco plot combine, and seed weights were reported on a $13 \%$ moisture basis.

Apothecium production was examined after the soybean canopy closed, especially during the period of soybean flowering, because $S$. sclerotiorum initially infects soybean flowers. The growth stages when diseased plants were first observed were also recorded, except at the Mason City location. In Iowa, symptomatic plants are usually visible after mid-August and the plants with latent infections continue to develop into symptomatic plants until September (23). Disease incidence, defined as the percentage of plants killed in a plot, was recorded at soybean growth stage R7 (10) in early September. A single assessment instead of disease progress curves over the season was used because of the narrow infection window of this disease. Plants in the center two rows of each plot were rated for disease by two people and an average was recorded. Reaction of each cultivar was characterized as percentage of plants killed. The fewer plants killed in a cultivar, the lower the disease incidence.

Data analysis. Analysis of variance (ANOVA; SAS Institute, Cary, NC) was conducted to determine the level of variation between replications using disease incidence or yield as the independent variable. Individual cultivar means were calculated for each experiment. To compare the response of cultivars to disease among experiments, cultivars were arbitrarily grouped into three disease incidence levels

Table 1. Summary of levels of disease incidence from Sclerotinia stem rot (Sclerotinia sclerotiorum) in soybean cultivars at different locations in 1996 (63 entries) and 1997 (64 entries)

\begin{tabular}{lccrc}
\hline & \multicolumn{3}{c}{ Level of disease incidence $(\boldsymbol{\%})^{\mathbf{a}}$} & \\
\cline { 2 - 4 } Environment & $<\mathbf{3 0}$ & $\mathbf{3 1 - 6 0}$ & $>\mathbf{6 0}$ & Mean $(\boldsymbol{\%})^{\mathbf{b}}$ \\
\hline Ames, 1996 & 61 & 2 & 0 & 23 \\
Ames, 1997 & 64 & 0 & 0 & 8 \\
Humboldt, 1996 & 20 & 33 & 10 & 74 \\
Kanawha, 1996 & 45 & 14 & 4 & 60 \\
Mason City, 1997 & 40 & 17 & 7 & 73 \\
\hline
\end{tabular}

${ }^{a}$ Disease incidence was measured as percentage of soybean plants killed at growth stage R7. The incidence data were grouped into three levels.

${ }^{\mathrm{b}}$ Mean incidence of susceptible standard cvs. Asgrow A2242 and Williams 82.
( 0 to 30,31 to 60 , and $>60 \%$ ) labeled low, medium, and high, and the number of cultivars at each level was determined. Average disease incidences of susceptible standard cultivars were also calculated as an indication of conduciveness of the environment (location-year) to disease.

To determine the consistency of the response of cultivars to disease in our experiments, correlation analyses were conducted for disease ratings among environments (location-year) which had high levels of disease incidence in susceptible checks. In this analysis, only 19 cultivars which were included in all environments were used. Pearson correlation coefficients between any two environments were calculated by the CORR procedure in SAS using incidences at two locations as variables. A significant coefficient indicated consistency of cultivar response between two locations. Similar analyses were done with yield data.

The relationship between disease incidence and yield was determined by plotting yield data for individual cultivars against disease incidence for each experiment. The linear trends were first examined before linear regression analyses were conducted. The SAS REG procedure was used in regression to determine intercepts, regression slopes, and coefficients of determination. The intercepts and slopes represent maximum yield in the absence of disease and yield loss (in kilograms) per unit of disease incidence. The residuals were plotted and examined for normal distributions. We also mined trends between maturity clas incidence of individual cultivars against maturity class for each location. Simple linear regression analyses were performed to determine the significance of maturity effects on disease incidence.

\section{RESULTS}

Disease incidences were generally high at northern Iowa sites but low at the Ames location in central Iowa. Low initial disease incidences were observed at Ames in 1996, with final incidences of susceptible checks averaging $23 \%$ (Table 1). Only two cultivars had incidences greater than $30 \%$ (Table 1). The field at Ames was flooded for two days in late June, which may have contributed to the low disease level. The and disease incidence by plotting average 
incidence was low again in 1997, with less than $10 \%$ incidence for all cultivars, perhaps because of relatively dry weather in July and early August. Because of low disease levels for the experiments at Ames, soybeans were not harvested for yield and disease data at this location were not used in quantitative comparisons for consistency in response to $S$. sclerotiorum (see below).

At northern Iowa locations, average disease incidences in susceptible standard cultivars were greater than $60 \%$ in both years (Table 1). Apothecia appeared earliest at Humboldt in the 1996 season, and diseased plants were first observed as early
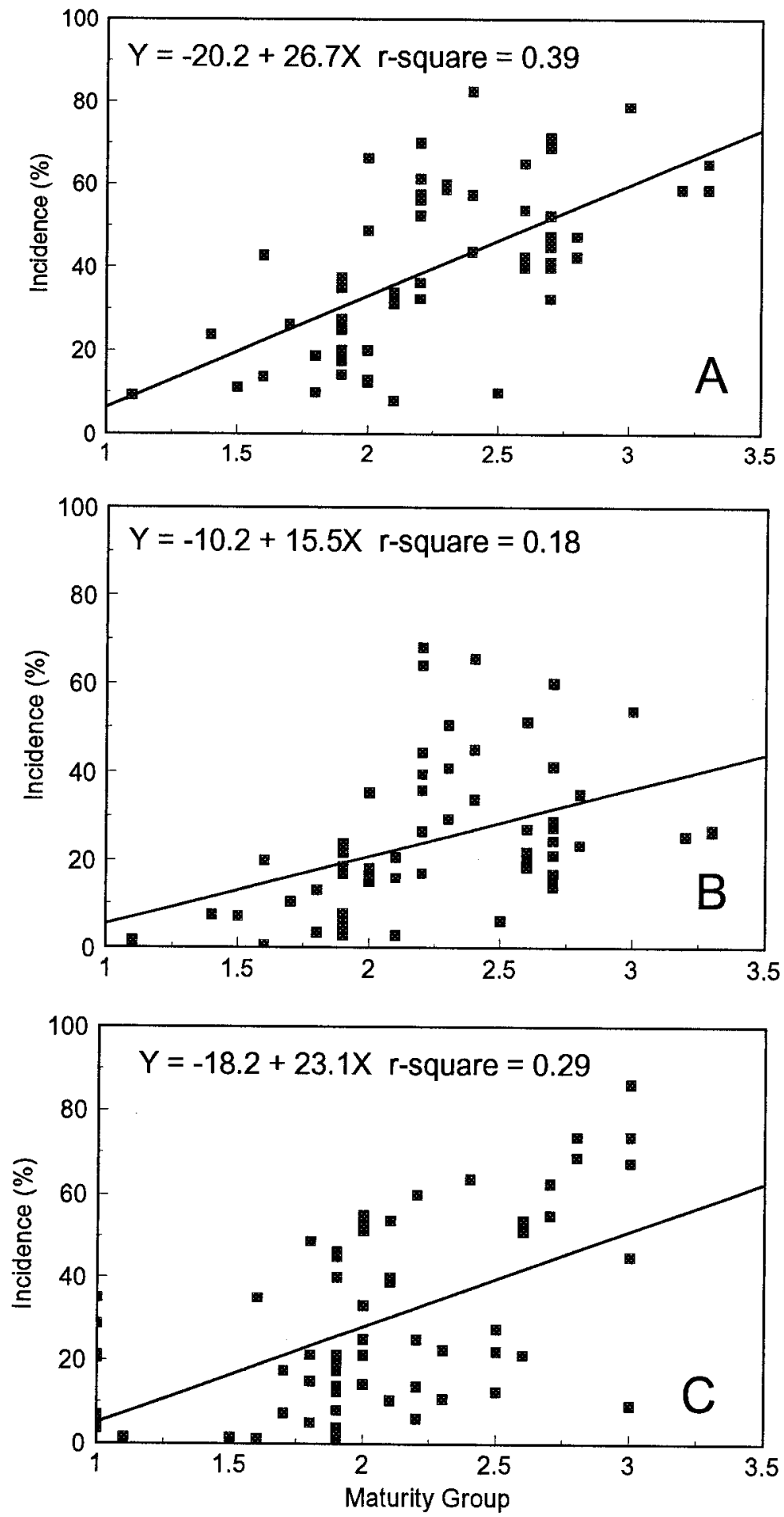

Fig. 1. Results of regression analysis between cultivar response to Sclerotinia stem rot (Sclerotinia sclerotiorum) and maturity group for experiments at (A) Humboldt in 1996, (B) Kanawha in 1996, and (C) Mason City in 1997. An experiment at each location was conducted in a field naturally infested by $S$. sclerotiorum and each experiment included 63 or 64 cultivars. One data point represents a mean of a cultivar from four replicated plots. All coefficients of determination were significant at $P$ $<0.01$.

as late July. At Kanawha, apothecia were observed in late July and scattered diseased plants were observed in early August. Disease onset at Mason City in 1997 occurred late compared with the 1996 observations at Kanawha and Humboldt. At the Kanawha and Mason City locations, disease incidences on 40 and 45 cultivars, respectively, were $<30 \%$ (Table 1). The Humboldt site had 33 cultivars with disease incidences ranging from 31 to $60 \%$, over twice as many as at other locations. Under all environmental conditions, no more than 10 cultivars at each site had disease incidences $>60 \%$.

Maturity effects. In our experiment, maturity class significantly affected the level of Sclerotinia stem rot (Fig. 1). There was a significant linear relationship between disease incidence and maturity groups $\left(r^{2}=0.18\right.$ to $\left.0.39, P<0.01\right)$, in that the cultivars in maturity groups II and III had higher disease incidences than cultivars in the maturity group I (Fig. 1). Higher values of $r^{2}$ (Fig. 1) were obtained for data from Humboldt and Mason City than from the Kanawha plots, which had lower disease incidence in susceptible standard cultivars. The values of regression slopes in these two environments indicated an increase of 23 to $26.7 \%$ incidence units per maturity class in our experiments.

Consistency of cultivar reaction. Responses of cultivars to disease, as measured by incidence or yield, were consistent for all three locations where disease incidences in susceptible standards were high (Table 2). For the 19 cultivars that were used in all locations in both years, incidence was consistently low on cv. Pioneer 9163 and consistently high on cv. Lewis Hybrids 276. Disease incidences in resistant standard cvs. Corsoy 79 and S19-90 were among the lowest in all experiments (Table 2). Significant Pearson correlation coefficients $(P<0.0001)$, which measured the consistency of response of the 19 soybean cultivars to $S$. sclerotiorum in terms of incidence between two locations, were 0.94 for Humboldt-Kanawha, 0.88 for Humbolt-Mason City, and 0.80 for Kanawha-Mason City. Significant Pearson correlation coefficients $(P<0.009)$ for consistency of yield response were 0.81 for Humbolt-Kanawha, 0.75 for HumboltMason City, and 0.58 for Kanawha-Mason City. For all 63 cultivars used in 1996, correlation coefficients were 0.86 for incidence and 0.67 for yield between Humboldt and Kanawha. Individual cultivars inconsistent in disease response over years and locations were also observed. For example, cv. DSR-277 had an incidence of $55 \%$ at Mason City and $40 \%$ at Humboldt, but only $13.9 \%$ at Kanawha.

Disease incidence and yield. The incidence-yield relationship of individual locations was well described by linear regression models as indicated by highly significant $(P<0.0001, n=63$ or 64$)$ coef- 
ficients of determination $\left(r^{2}\right)$ of $0.83,0.61$, and 0.59 for Humboldt, Kanawha, and Mason City, respectively (Fig. 2). The residual plots showed a normal distribution in each experiment, with a few values in the Mason City experiment skewed towards high incidence. The slope value for the Humboldt site $(b=33.5)$ was greater than those of Kanawha $(b=22.0)$ and Mason City $(b=17.0)$. The intercepts of regression, which are indications of yield potential in the absence of disease, ranged from 3,410 to $3,970 \mathrm{~kg} / \mathrm{ha}$ and were not significantly different $(P<0.01)$ among the three locations.

\section{DISCUSSION}

In these studies, we tested 63 to 64 soybean cultivars of maturity groups I to III in different environments and found that some cultivars of maturity group II, such as DSR 220 and SOI 260, had consistently low disease. Correlation analyses of disease incidence among environments showed consistent disease incidence and yield response to Sclerotinia stem rot at the northern Iowa locations but not at the central Iowa location. Soybean maturity class significantly $(P<0.01)$ influenced the disease incidence, with an average increase of 23 to $26 \%$ incidence units per maturity class as indicated by regression slopes for data from Humboldt and Mason City. There were significant linear relationships between yield and disease incidence $(P<$ $0.0001)$ and between incidence and maturity class $(P<0.01)$. Because information on performance of soybean cultivars under field conditions is essential for future studies on resistance to Sclerotinia stem rot in controlled conditions such as greenhouses, our results provide a database for the development of inexpensive, rapid, and dependable laboratory or growth chamber methods of cultivar tests with current genetic materials.

It is well established in disease loss assessment studies that there are often great variations in yield loss to disease incidence relationships when soybean diseases are studied (21). In soybean, these variations are largely due to the plants' spatial compensation capacity. Available studies on soybean Sclerotinia stem rot (11) also show a greater variation under a yield-loss model. Our results, however, achieved higher coefficients of determination, with 59 to $83 \%$ of variation in yield explained by disease incidence. The slopes indicate that yield reduction per 10 units of disease incidence ranged from 170 to $330 \mathrm{~kg} / \mathrm{ha}$. The smaller regression slope for the $\mathrm{Ka}$ nawha experiment compared with that of Humboldt can be explained by the late occurrence of this disease at Kanawha. Further, the relationship between disease incidence and yield loss was well described by a simple linear regression as indicated by the higher $r^{2}$ values. Such a good fit for a disease whose occurrence is highly erratic suggests a uniformity of inoculum among plots within a location.

Variation in incidence among locations for a given cultivar may have been due to variability in environment, genetic variability of the pathogen, or time of infection. The differences in regression slopes among the three locations may be attributed to differences in the time of epidemic onset. Among the three common models used for yield loss assessment, the singlepoint model, the multiple-point model, and the model of area under the disease progress curve (AUDPC), the parameters of the single-point model, which we used in this study, are affected by the time of disease onset and rate of disease development when used to estimate yield losses caused by foliar diseases (21). For instance, using the estimated maximum yields (MY) and slope values $(b)$, we can calculate percent yield loss $=(\mathrm{MY}-b \times$ incidence $) / \mathrm{MY}$. Using MY and $b$ values, we calculated that, at $70 \%$ disease incidence, the estimated yield loss was 59\% at Humboldt and $45 \%$ at Kanawha. The difference between the two locations may result from the earlier infection in Humboldt, because we observed that apothecium production was at least 1 week earlier at Humboldt than at Kanawha. This indicates that care must be taken when estimates from a single-point model are used for disease loss assessment.

Complete resistance to Sclerotinia stem rot has not been reported, although consistent differences in cultivar response have been observed (13). Consistent cultivar response to Sclerotinia stem rot is critical to growers in selection of cultivars and other management decisions. Our study suggests that a consistent response of given cultivars can be achieved when experiments are conducted in fields which have high inoculum density and environmental conditions conducive to the disease. Inoculum uniformity and conditions conducive for disease development in the three environments were indicated by the consistently high disease incidence in susceptible standards (Table 2). Consistency in cultivar response measured by disease incidence was also indicated by correlation coefficients $(R)$ greater than 0.80 among the three experiments. The disease incidences of check cvs. Novartis S19-90, Corsoy 79, A2242, and Williams 82 was

Table 2. Yield and disease incidence of 19 soybean cultivars infected by Sclerotinia sclerotiorum in experiments conducted in 1996 and 1997 at three Iowa locations

\begin{tabular}{|c|c|c|c|c|c|c|c|c|}
\hline \multirow[b]{2}{*}{ Company } & \multirow[b]{2}{*}{ Cultivar } & \multirow[b]{2}{*}{ Maturity } & \multicolumn{2}{|c|}{1996 Humboldt } & \multicolumn{2}{|c|}{1996 Kanawha } & \multicolumn{2}{|c|}{1997 Mason City } \\
\hline & & & Yield $^{\mathrm{a}}$ & Incidence $^{b}$ & Yield & Incidence & Yield & Incidence \\
\hline Custom Farm Seed & CFS 181 & 1.8 & 3349.1 & 10.0 & 3517.2 & 3.4 & 3267.6 & 21.3 \\
\hline Dairyland Seed Co. & DSR-220/STS & 2.2 & 2831.2 & 32.5 & 2918.7 & 26.6 & 3059.9 & 25.0 \\
\hline Dairyland Seed Co. & DSR-277 & 2.7 & 2326.9 & 40.0 & 3066.6 & 13.9 & 2777.4 & 55.0 \\
\hline Hy-Vigor Seeds & Hy-Vigor 1150 & 1 & 3739.1 & 11.3 & 3248.2 & 7.1 & 2985.9 & 6.8 \\
\hline Lewis Hybrids & 276 & 2 & 1560.2 & 71.3 & 2400.8 & 60.0 & 2683.3 & 52.5 \\
\hline Mark Seed Co. & MRK 9519 & 1.9 & 3994.7 & 13.0 & 3382.7 & 15.0 & 3207.8 & 18.8 \\
\hline Midwest Seed Gen. & G1885 & 1 & 3799.6 & 14.3 & 3584.4 & 7.8 & 3127.1 & 35.0 \\
\hline Novartis & S19-90 & 1.9 & 3174.2 & 17.5 & 3362.5 & 2.8 & 3221.3 & 2.0 \\
\hline Pioneer Hi-Bred & 9163 & 1.6 & 3503.7 & 13.8 & 3766.0 & 0.5 & 3113.7 & 1.3 \\
\hline Sand Seed Service & SOI 26 & 2 & 3685.3 & 12.5 & 3234.7 & 16.3 & 3133.9 & 21.3 \\
\hline Terra International & TS194 & 1 & 3604.6 & 17.5 & 2952.3 & 4.5 & 3248.2 & 28.8 \\
\hline Terra International & TS223 & 2 & 2569.0 & 56.3 & 2757.3 & 35.9 & 2279.8 & 55.0 \\
\hline Asgrow & A2242 & 2.2 & 1768.7 & 70.0 & 2024.2 & 64.0 & 2723.6 & 60.0 \\
\hline University of Illinois & Corsoy 79 & 2.1 & 3631.5 & 8.0 & 3133.9 & 2.8 & 2750.5 & 10.5 \\
\hline University of Minnesota & Dassel & 1.1 & 3288.5 & 9.3 & 2286.5 & 1.6 & 2710.2 & 1.5 \\
\hline University of Illinois & Williams 82 & 3 & 948.2 & 78.8 & 1560.2 & 53.8 & 901.2 & 86.3 \\
\hline Iowa State University & BSR101 & 1.9 & 2683.3 & 27.5 & 2690.0 & 18.4 & 2965.7 & 12.5 \\
\hline Ohio State University & Bell & 1.6 & 2199.1 & 42.8 & 2790.9 & 19.9 & 2293.2 & 35.0 \\
\hline Iowa State University & Kenwood & 2.1 & 2891.8 & 33.8 & 2925.4 & 20.6 & 2663.1 & 40.0 \\
\hline $\operatorname{LSD}_{0.05^{c}}$ & $\ldots$ & $\ldots$ & 665.8 & 14.5 & 672.0 & 12.7 & 450.6 & 17.5 \\
\hline
\end{tabular}

a Yield in $\mathrm{kg} / \mathrm{ha}$.

${ }^{\mathrm{b}}$ Disease incidence was measured as percentage of plants killed at growth stage R7 (10).

${ }^{\mathrm{c}} \mathrm{LSD}=$ least significant difference at $P<0.05$ 
very consistent over locations. In previous studies $(7,8,13)$, cvs. Corsoy or Corsoy 79 were consistently higher in resistance ratings to Sclerotinia stem rot, while cv. Williams 82 was among the most susceptible. In our tests, the disease incidence levels for cv. Corsoy 79 were generally among the lowest and those of cv. Williams 82 were highest. Further analysis on the pedigrees of these cultivars may provide insights on how genetic backgrounds influence cultivar response to $S$. sclerotiorum.
Cultivars with disease incidences less than $30 \%$ can be considered to have good field resistance and should yield satisfactorily. The differences among experiments in the number of cultivars having disease incidences in the range of 30 to $60 \%$ (Table 1) indicates that over-estimation of field resistance can occur when environmental conditions are not conducive for the disease, such as happened in the experiments at Ames. The inconsistency in response of a cultivar across experiments may be at-
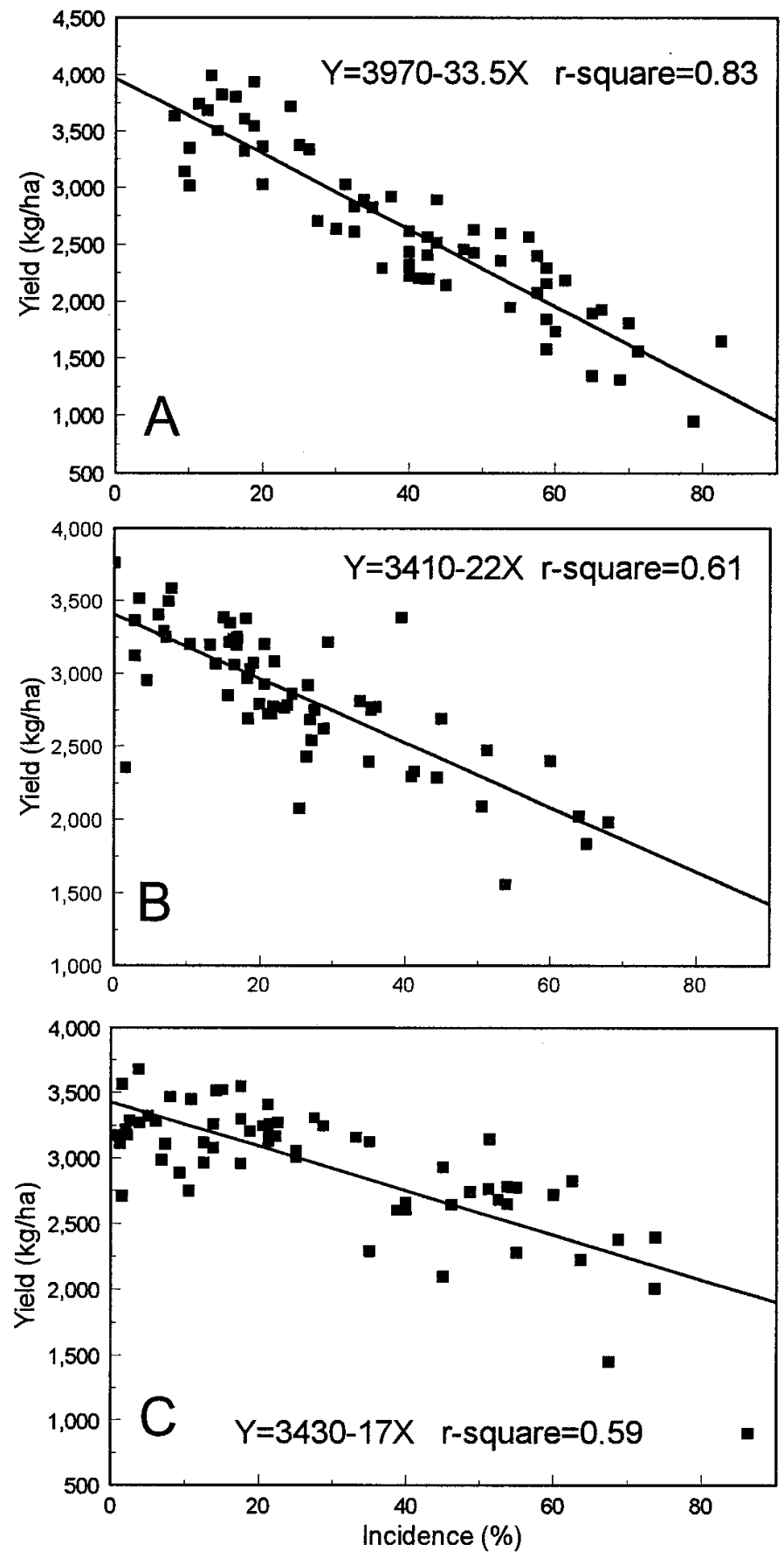

Fig. 2. Results of regression analysis between soybean grain yield and percentage incidence of Sclerotinia stem rot (Sclerotinia sclerotiorum) for experiments at (A) Humboldt in 1996, (B) Kanawha in 1996, and at (C) Mason City in 1997. An experiment at each location was conducted in a field naturally infested by S. sclerotiorum and each experiment included 63 or 64 cultivars. One data point represents a mean of a cultivar from four replicated plots. All coefficients of determination were significant at $P<0.0001$.

tributed to the fact that disease incidence is affected by, apart from genetic variation of a cultivar and $S$. sclerotiorum, the environment during and after the soybean flowering period. For example, moisture and temperatures during flowering affect time and amount of apothecium production $(1,4,19,26)$ and post-infection disease development (4). Light intensity can also influence susceptibility (17). To reduce the inconsistency of field studies, experiments ensured by high inoculum density and favorable environmental conditions are critical.

The number of cultivars used in this study allowed us to demonstrate statistically a significant linear relationship between disease incidence and maturity class for soybean Sclerotinia stem rot because late-maturity cultivars had higher disease levels than those in early-maturity groups (Fig. 1). Our results are consistent with Buzzel et al. (5). It is well established that $S$. sclerotiorum infects plants mainly through senescent flowers $(11,20)$. The longer the flowering period, the greater the window of infection if the environmental conditions are conducive for disease development. Cultivars in maturity group III have longer and later flowering periods which may have resulted in higher amounts of infection. The effects of maturity class on incidence level were greater when environmental conditions were more conducive to disease. This was supported by the fact that higher $r^{2}$ values were obtained from experiments having higher levels of disease in susceptible standards (Humboldt and Mason City). It is also interesting that many cultivars in later maturity groups had relatively low disease incidence ratings and maturity class only explained a very small portion of variation in disease incidence. This clearly suggests that genetic mechanisms other than maturity factor may mainly impact the resistance level for these cultivars.

\section{ACKNOWLEDGMENTS}

We thank C. Martinson, K. Mulenbruch, D. Reuber, B. Voss, and S. Wegulo for their assistance.

\section{LITERATURE CITED}

1. Abawi, G. S., and Grogan, R. G. 1979. Epidemiology of plant diseases caused by Sclerotinia species. Phytopathology 69:899-904.

2. Anderson, F. N., Steadman, J. R., Coyne, D. P., and Schwartz, H. F. 1974. Tolerance to white mold in Phaseolus vulgaris dry edible bean types. Plant Dis. Rep. 58:782-784.

3. Boland, G. J., and Hall, R. 1987. Evaluating soybean cultivars for resistance to Sclerotinia sclerotiorum under field conditions. Plant Dis. 71:934-936.

4. Boland, G. J., and Hall, R. 1988. Epidemiology of Sclerotinia stem rot of soybean in Ontario. Phytopathology 78:1241-1245.

5. Buzzell, R. I., Welacky, T. W., and Anderson, T. R. 1993. Soybean cultivar reaction and row width effect on Sclerotinia stem rot. Can. J. Plant Sci. 73:1169-1175.

6. Chamberlain, D. W. 1951. Sclerotinia stem rot of soybean. Plant Dis. Rep. 35:490-491. 
7. Chun, D., Kao, L. B., Lockwood, J. L., and Isleib, T. G. 1987. Laboratory and field assessment of resistance in soybean to stem rot caused by Sclerotinia sclerotiorum. Plant Dis. 71:811-815.

8. Cline, M. N., and Jacobsen, B. J. 1983. Methods for evaluating soybean cultivars for resistance to Sclerotinia sclerotiorum. Plant Dis. 67:784-786.

9. Doupnik, B., Jr. 1993. Soybean production and disease loss estimates for north central United States from 1989 to 1991. Plant Dis. 77:1170-1171.

10. Fehr, W. R., Caviness, C. E., Burmood, D. T., and Pennington, J. S. 1971. Stage of development descriptions for soybeans, Glycine $\max (\mathrm{L})$ Merill. Crop Sci. 11:929-931.

11. Grau, C. R. 1988. Sclerotinia stem rot. Pages 56-66 in: Compendium of Soybean Diseases, 3rd edition. J. B. Sinclair and P. A. Backman, eds. APS Press, St. Paul, MN.

12. Grau, C. R. 1988. Sclerotinia stem rot of soybean. Pages 47-48 in: Soybean Diseases of the North Central Region. T. D. Wyllie and D. H. Scott, eds. APS Press, St. Paul, MN.

13. Grau, C. R., Radke, V. L., and Gillespie, F. L. 1982. Resistance of soybean cultivars to Sclerotinia sclerotiorum. Plant Dis. 66:506-508.

14. Hoffman, D. D., Hartman, G. L., Mueller, D. S., Leitz, R. A., Nickell, C. D., and Petersen, W. L. 1998. Yield and seed quality of soybean cultivars infected with Sclerotinia scle- rotiorum. Plant Dis. 82:826-829.

15. Nelson, B. D., Helms, T. C., and Kural, I. 1991. Effect of temperature and pathogen isolate on laboratory screening of soybean for resistance to Sclerotinia sclerotiorum. Can. J. Plant Sci. 71:347-352.

16. Nelson, B. D., Helms, T. C., and Olson, M. A. 1991. Comparison of laboratory and field evaluations of resistance in soybean to Sclerotinia sclerotiorum. Plant Dis. 75:662-665.

17. Pennypacker, B. W., and Risius, M. L. 1997. Stability analysis of soybean cultivar response to Sclerotinia sclerotiorum in greenhouse screening for resistance. (Abstr.) Phytopathology 87:S76.

18. Schwartz, H. F., Casciano, D. H., Asenga, J. A., and Wood, D. R. 1987. Field measurement of white mold effects upon dry beans with genetic resistance or upright plant architecture. Crop Sci. 27:699-702.

19. Schwartz, H. F., and Steadman, J. R. 1978. Factors affecting sclerotium populations of, and apothecium production by, Sclerotinia sclerotiorum. Phytopathology 68:383-388.

20. Steadman, J. R. 1983. White mold-a serious yield-limiting disease of bean. Plant Dis. 67:346-350.

21. Teng, P. S. 1987. Quantifying the relationship between disease intensity and yield loss. Pages 105-113 in: Crop Loss Assessment and Pest Management. P. S. Teng, ed. APS Press, St. Paul, MN.
22. Tu, J. C., and Beversdorf, W. D. 1982. Tolerance to white mold (Sclerotinia sclerotiorum (Lib.) De Bary) in Ex Rico 23, a cultivar of white bean (Phaseolus vulgaris L.). Can. J. Plant Sci. 62: 65-69.

23. Wegulo, S. N. 1997. Soybean cultivar responses to and epidemiological studies of Sclerotinia sclerotiorum. Ph.D. thesis, Iowa State University, Ames.

24. Wegulo, S. N., Lundeen, P., Yang, X. B., and Martinson, C. A. 1996. Effects of tillage, row spacing, cultivars, and benomyl on Sclerotinia stem rot. (Abstr.) Phytopathology 86:S64.

25. Whigham, K. 1997. Soybean management for increased yield. Pages 17-20 in: Proc. 9th Annu. Integrated Crop Manage. Conf. Iowa State University, Ames.

26. Williams, J. R., and Stelfox, D. 1980. Influence of farming practices in Alberta on germination and apothecium production of sclerotia of Sclerotinia sclerotiorum. Can. J. Plant Pathol. 2:169-172.

27. Wrather, J. A., Anderson, T. R., Arsyad, D. M., Gai, J., Ploper, L. D., Porta-Puglia, A. Ram, H. H., and Yorinori, J. T. 1997. Soybean disease loss estimates for the top 10 soybean producing countries in 1994. Plant Dis 81:107-110.

28. Yang, X. B., Workneh, F., and Lundeen, P. 1998. First report of sclerotium production by Sclerotinia sclerotiorum in soil on infected soybean seeds. Plant Dis. 82:264. 